\title{
Technical and Economic Study of Powering Poultry Farm in Egypt Using PV-Biomass on-grid Energy Generation System: Case Study
}

\author{
T. A. BOGHDADY ${ }^{1}$, ALI J. ALAMER ${ }^{1}$, MINA M. YOUSEF ${ }^{1}$, AHMED M. ELSHAFEE $^{2}$, M. A. \\ MOSTAFA HASSAN ${ }^{1}$, A. MONEM SEIF ${ }^{1}$ \\ ${ }^{1}$ Electrical Power engineering Dept., Faculty of engineering, \\ ${ }^{1}$ Cairo university, ${ }^{2}$ Ahram Canadian University, \\ ${ }^{1}$ Giza, \\ ${ }^{1}$ EGYPT. \\ ${ }^{2}$ Ahram Canadian University, Faculty of engineering, Giza, EGYPT
}

\begin{abstract}
The main goal of this work is to find economical alternative energy supply solution for poultry industry in Egypt. By studying the economic feasibility of using hybrid renewable energy resources as main source of power for existing poultry farm in Egypt to reduce existing operational cost of energy and add resilience and reliability dimensions for the operation of poultry farm in rural locations. In addition to reducing the environmental impact of using poultry litter in its fundamental form. This hybrid system connected to grid is used in the company to avoid instability problem in which the company suffered when they applied biomass energy source as main power source to their farm in Lebanon. The grid will be used as energy storage during the excess energy production form the hybrid system and to add some resilience and reliability dimensions to the hybrid system to prevent instability to the farm 's grid due to the high penetration of renewable energy. The economic feasibility is evaluated of this configuration using HOMER versus different configurations and sizes for these systems including the existing situation of depending only on grid as main source of energy. The results showed that the best configuration is 400 $\mathrm{kW}$ biomass generator, and $500 \mathrm{~kW}$ PV plant will satisfy the average demanded load of $9660 \mathrm{kWh}$ daily with using the grid as backup energy source. The cost of energy for this configuration will be $0.0894 \$ / \mathrm{kWh}$ which is lower than continuing existing situation depending on the grid as main source of power in which its Cost of Energy (COE) will reach during the lifetime of the project to $0.184 \$ / \mathrm{kWh}$ due to the increase in COE in Egypt by $8 \%$.
\end{abstract}

Key-Words: Biomass, Grid, Homer, Photovoltaic, Poultry, Renewable Energy.

Received: December 11, 2020. Revised: April 5, 2021. Accepted: April 8, 2021. Published: April 13, 2021.

\section{Introduction}

Economy, Energy, environment, and sustainability are four interrelated areas taking a shortest connection for the growth of all countries [1]. At economies of precipitously rising developing countries, the continuously demand on electricity is growing. The electricity is considered as one of the leading factors in a rising economy, besides growing need sets enormous pressure on energy infrastructure of the countries to meet these needs. Draining gas, in addition to oil reserves, joined with rising worries of environmental pollution, have explored to find the suitable energy from renewable resources available [2-3].

Also, the demand on electricity shows an essential role in housing of poultry. the electricity is used in different applications inside poultry houses, first and foremost ventilation, lighting, heating, cooling, and the electric motors that operate the feeding lines [4]. Consequently, to power the previous mentioned poultry house equipment, it is preferable to use renewable energy systems to design system to fulfill these requirements. Most of renewable energy resources such as solar, tidal, wind, and biomass are fluctuating due to nature or vary during the season or the daytime. To attain reliability, it is possible to combine more than or equal two energy sources such as wind, biomass, solar photovoltaic and connected to grid optimally to have a hybrid generation system [5].

Economists considered Poultry products being as one of the highly critical resources of protein of lowcost, wherever the red meat (animal meat) is extremely expensive as contrasted with the white meat (poultry 
meat). As well as the latter is extreme economic profit categorizes poultry production because of short production cycle, the types of animal production is also associated with capital speedy in which poultry production cycle is around seven to eight weeks in the meantime the production bovine cycle is around three to twelve months. Consequently, at production cycle of poultry, the cycle of capital can be frequent 7 periods around the year. Similarly, the production of poultry requires a smaller area rather than what production of further animal's needs. The production of Poultry can subsidize to solve the problem of the unemployment. [6-8]. Also, the production of Poultry can subsidize the strategy of security state of food and the policy.

The present situation of energy in Egypt indicates that traditional energy sources cannot meet future energy demand besides an increase in the cost of energy, which directs to surge in products cost. In upcoming years, it is necessarily to shift from traditional resources to resources of renewable energy to meet the demand of energy for various parts, especially remote areas, in addition to differ applications. Hence, the combination of renewable energy that can extracted from litter that comes out of poultry and cattle houses have countless potential to increase supplies of the food with a natural resource of energy which does not generate pollution to the air or cause problem to global climate, particularly at the private food sector.

One of the big companies at the private food sector working in the poultry field in Egypt called WADI group (WG) is planning to transfer all their poultry farms to the Western desert in Egypt near Aswan due to biosecurity. The location of the farms has a promising opportunity to use and integrate renewable energy such as biomass and solar energy with the Egyptian national grid to power the farms and reduce the cost of energy, which inevitably affects the cost of products. The principal aim of this article is to study the economic feasibility and design optimum size of grid connected renewable energy configuration that capable of fulfilling the needs of farms with a consumption of $9,660 \mathrm{kWh} /$ day and initial peak load around $712.9 \mathrm{~kW}$ to supply poultry houses situated near the Aswan governorate at Egypt. So, to fulfill the requirements of load, and mitigate the variations due to non-linear seasonal along with equipment limitations achieves the best configuration of hybrid renewable energy resources for the poultry houses. So, to reach this goal, The purchased license of the application of the National Renewable Energy Laboratory's (NREL) software called "Hybrid Optimization Model for Electric Renewable (HOMER) version 3.13.3" is used to size the system, as well as optimize. This study is different than other studies such as [9] by applying the concept of hybrid PV- Biomass with on grid system on the bigger application scale and bigger size of system and using the grid as energy storage instead of using batteries which will also play role in stability of farm's grid. This study aims to support the company vision for decreasing the cost of energy used to operate their farm in rural area at desert and add resilience and redundancy dimensions for the existing situation by using the existing available renewable energy resources at the location of farm to decrease dependence on the national grid at this rural location. The work also aims to solve main problem that faced the company at their branch in Lebanon when they applied only waste to energy technology for poultry farm and had instability issue for the farm's grid in Lebanon as connecting only biomass generator. This work illustrates of the benefits of combing different renewable energy resources with grid to solve the fluctuation energy generation problem of renewable resources. This paper is organized as follow: section 2 identifies the methodology that is used to build the model for the proposed system. the system design and analysis for the load types inside poultry houses are reviewed in section 3 . section 4 shows the result of simulations of different configurations and illustrates the best economical feasible configuration of the system with more technical data about the consumption of fuels and energy imported from the grid during the life cycle of the project., and finally, the conclusions, recommendation and future work are stated in section $\mathrm{V}$ and VI, respectively.

\section{Methodology}

The national renewable energy laboratory in USA developed HOMER software for designing optimally as well as evaluates the economic feasibility of the grid connected with solar and biomass energy generation system. The mentioned tool (HOMER) is considered as effective program for the best possible sizing, designing, and arrangement of grid connected renewable energy generation systems through evaluating techno-economic analysis for both on \& off grid-connected energy generation systems. The inputs are entered on HOMER such as electrical demands to accomplish the simulations based on different configurations for energy generations systems with different combinations of components to generate the most optimally configurations for the energy generations system then arranged those configurations in ascending order according to lowest $\mathrm{COE}$ and Net present cost (NPC). The HOMER'S goal is to minimize the objective function that subjected to required constraints, as any other optimization tool such as GA, PSO and Linearized Biogeography-Based Optimization (LBBO) [10-11], to optimize the configurations of energy generation systems.

In this analysis, in HOMER, the net present cost is considered as the objective function, in which is the 
present cost of system without the adding the returns. connecting to grid, power balance, and other technical constraints are considered as the constraints. it simulates the system configurations through balancing the energy at every hour then calculate the total electric demands for each hour where a system generates possibly [7]. the analysis features inside HOMER illustrates penetration percent of renewable energy generation systems as well as the impact of connection the load to the grid on both cost of energy as well as net present cost. The program accomplishes the analysis of pre-feasibility and do the optimization for design of the micro-grid energy generation systems at designing phase before its installed.

Typically, HOMER program can perform 3 tasks through simulating all the possible configurations, doing analysis for sensitive parameters, in addition to optimize the best configuration [12]. Previous to HOMER performs the based analysis for the grid connected solar/biomass energy generation system, assessing the load requirements for the poultry farms, and the available energy resources on the farm. performed a Pre-HOMER analysis.

Later, the user fed the load data into the software interface and using available equipment in the software performed analysis for the hybrid micro grid connected energy generation system, components, grid, and Loads are considered as 3 key types of hybrid renewable energy generation system's equipment. at this article, loads are electric loads, along with the components are biomass generators, $\mathrm{PV}$, plus the electric grid. HOMER modeled the characteristics of these components.

HOMER also considered Constraints for the sensitivity analysis according to the system requirements for life cycle cost analysis. the user can perform post-analysis to determine the final decision compared with on the market energy costs.

These energy market prices include the supply tariffs set by public sector distribution companies of Egypt.

\subsection{Demand Evaluation}

The grid connected PV- Biomass energy generation system is configurated to meet the demand requirements of the poultry houses inside the farm. The poultry farm is located at the Western desert near Aswan in Egypt. The main electrical demand requirements at the farm are driven by operational equipment, mechanical and electrical systems needed inside the farm, such as lighting systems, feeding lines, cooling pumps, and ventilation. The demand evaluation was accomplished precisely through calculating the electrical demands of 34 poultry houses located at the farm during the summer at peak time in which the Poultry farms electrical needs reach peaks. This demand calculations of 34 poultry houses located at the farm are listed in Tables 1, 2, and 3, respectively. The peak power load for the farm will be $712.9 \mathrm{~kW}$, while the energy demand will be $9666 \mathrm{kWh} /$ day.

Table 1. Equipment quantity and Consumption

\begin{tabular}{|c|c|c|}
\hline $\begin{array}{c}\text { Type of } \\
\text { Equipment }\end{array}$ & $\begin{array}{c}\text { \# of units per } \\
\text { house }\end{array}$ & $\begin{array}{c}\mathbf{k W} / \\
\text { unit }\end{array}$ \\
\hline Fan & 8 & 1.119 \\
\hline Lighting & 130 & 0.02 \\
\hline Cooling pump & 4 & 0.746 \\
\hline feeding line \#1 & 6 & 0.5595 \\
\hline feeding line \#2 & 3 & 1.119 \\
\hline Feeding pump & 2 & 93.25 \\
\hline
\end{tabular}

Table 2. Schedule of operation For Fans/ poultry house

\begin{tabular}{|c|c|c|c|c|}
\hline $\begin{array}{c}\text { Working } \\
\text { time }\end{array}$ & $\begin{array}{c}\text { \# fans } \\
\text { at } \\
\text { Jan.- } \\
\text { Feb. }\end{array}$ & $\begin{array}{c}\text { \# fans } \\
\text { at } \\
\text { Mar.- } \\
\text { Apr }\end{array}$ & $\begin{array}{c}\text { \# fans } \\
\text { at } \\
\text { May- } \\
\text { Sep. }\end{array}$ & $\begin{array}{c}\text { \# fans } \\
\text { at } \\
\text { Oct.- } \\
\text { Dec. }\end{array}$ \\
\hline $5 \mathrm{am}-9 \mathrm{am}$ & 2 & 3 & 4 & 3 \\
\hline $9 \mathrm{am}-11 \mathrm{am}$ & 3 & 4 & 6 & 5 \\
\hline $11 \mathrm{am}-1 \mathrm{pm}$ & 4 & 5 & 7 & 6 \\
\hline $1 \mathrm{pm}-4 \mathrm{pm}$ & 6 & 7 & 8 & 7 \\
\hline $4 \mathrm{pm}-6 \mathrm{pm}$ & 5 & 6 & 8 & 7 \\
\hline $6 \mathrm{pm}-7 \mathrm{pm}$ & 4 & 5 & 8 & 7 \\
\hline $7 \mathrm{pm}-9 \mathrm{pm}$ & 2 & 3 & 6 & 5 \\
\hline $9 \mathrm{pm}-5 \mathrm{am}$ & 1 & 2 & 4 & 3 \\
\hline
\end{tabular}

Table 3. Schedule of operation for lighting, Pumps $\&$ Feeding lines

\begin{tabular}{|c|c|c|}
\hline No. & Equipment type & Time of operation \\
\hline 1 & Lighting & $5: 00 \mathrm{am}-4: 00 \mathrm{pm}$ \\
\hline 2 & Cooling pump & 24 Hours \\
\hline 3 & Feeding pump & $8: 00 \mathrm{am}-6: 00 \mathrm{pm}$ \\
\hline 4 & feeding line \#1 \& \#2 & $5: 00 \mathrm{am}$ till 6:00 am \\
\hline
\end{tabular}

The daily electric load profile of the farm is displayed in Fig. 1. The demand is obviously varying throughout $24 \mathrm{~h}$ of a day, the peak electrical demand is always at the mid of day either in summer or winter. This peak happened due to the increasing in number of operating fans that are used in cooling and ventilation inside the poultry houses either in winter or summer to keep the air condition and humidity inside the houses constant as per company's requirement. The load consumption starts to decrease as the heat decrease. Other types of loads have constant consumption during summer or winter but vary during the daytime. From Fig. 2 the pattern of a load profile is the same across the year, while the different point is the scaling of load 
profile during the summer versus the winter. In the summer, the scale of the load profile is more significant than in the winter. This increase in scaling at summer appears clearly in Fig. 3.

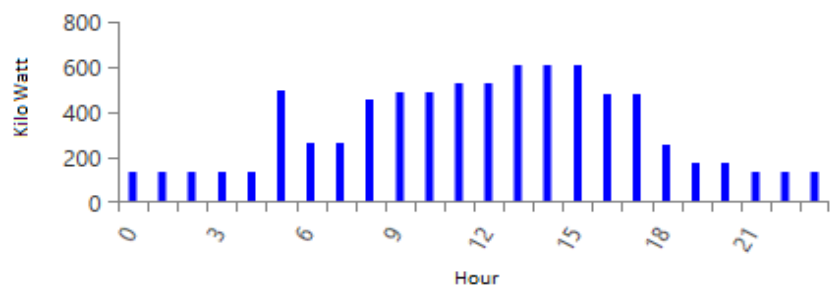

Fig.1 Daily profile.

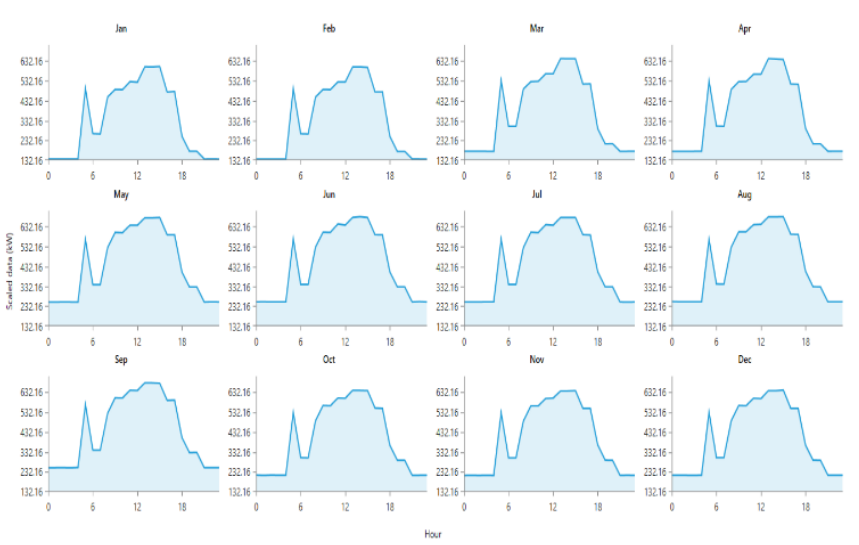

Fig.2 Daily profile per month.

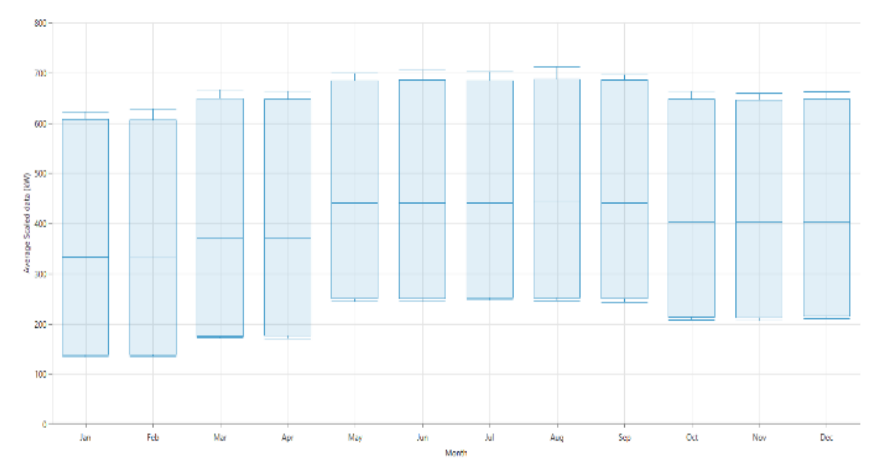

Fig.3 Scaled power monthly averages

\subsection{Accessible resources evaluation.}

For the present case, as the grid connected PV-Biomass energy generation system is considered. So, the available data that gives the comprehensive evaluation for the existing energy resources such as biomass and solar energy which illustrates as following:

\subsubsection{Accessible solar energy}

HOMER solar radiation data are used at the location at North: $22^{0} 59^{\prime} 29.4^{\prime \prime} \&$ East: $31^{0} 29^{\prime} 34.5$. this data is given from "National Aeronautics and Space Administration (NASA) surface meteorology and Solar Energy Database." NASA reported the annual scaled average solar radiations at this location is 6.24 $\mathrm{kWh} / \mathrm{m}^{2} /$ day, in addition to it was found the maximum solar radiations will be $7.752 \mathrm{kWh} / \mathrm{m}^{2} /$ day. As per the available data, the location of the farm has great solar potential as well as can efficiently generate energy through using PV panels. The below profile showing solar radiation and clearance index generated by the HOMER at this location is revealed in Fig. 4.

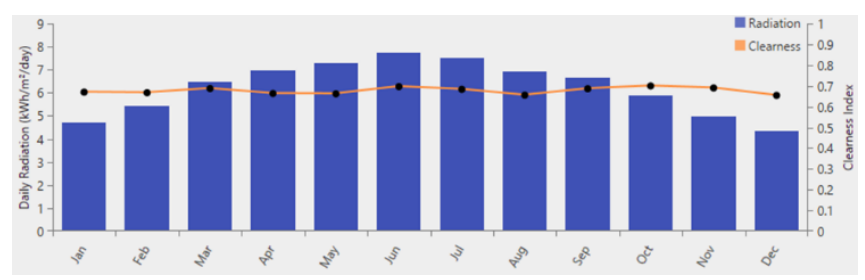

Fig.4 Monthly average solar GHI data from NREL

\subsubsection{Biomass resource assessment}

Biomass is considered as one of the most vital energy resources, that contains a huge range of various types of fuels with diverse compositions of chemicals coupled with combustion attributes. Its consumption is vital from energy source an energetic and an environmental perspective. in Egypt, the main 4 types of biomass energy sources that represents the potential of biomass energy sources are included agricultural residues (dedicated bioenergy crop residues), municipal solid wastes, animal wastes, and sewage sludge.

In [13], it illustrated the negative impact of using poultry litters as fertilizers in agriculture besides its impact on the environment. So, in this project, due to the availability of poultry litters from poultry houses that had great potential to convert it to electricity as well as the remote location of the farm from the agriculture area, it is recommended in [14-15] to use a biomass Fluidized bed gasifier. in this study, the Last 3 years data in Fig. 5 for production of poultry litters at WADI GROUP farm were taken into consideration to find the average expected amount of poultry litter production on monthly basis as illustrated in Fig. 6 .

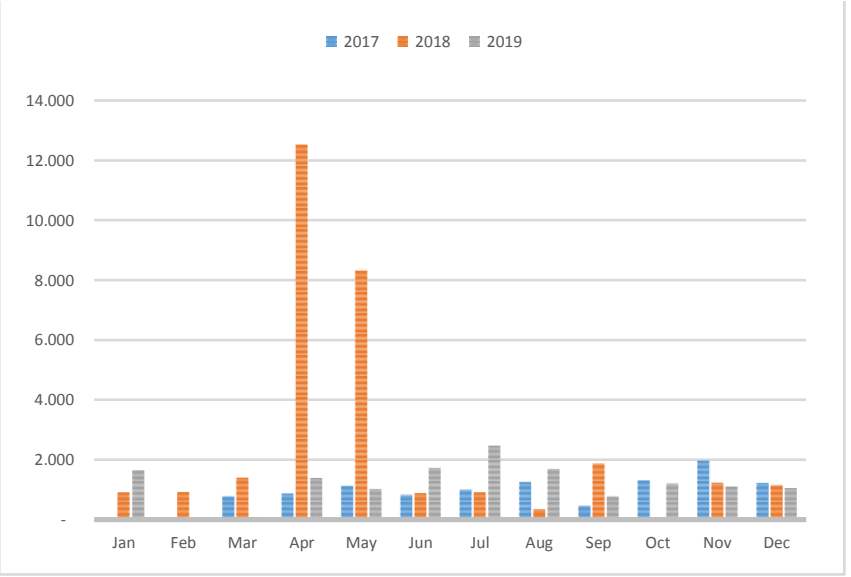

Fig.5 Poultry Litter production at WADI Group during last three years. 


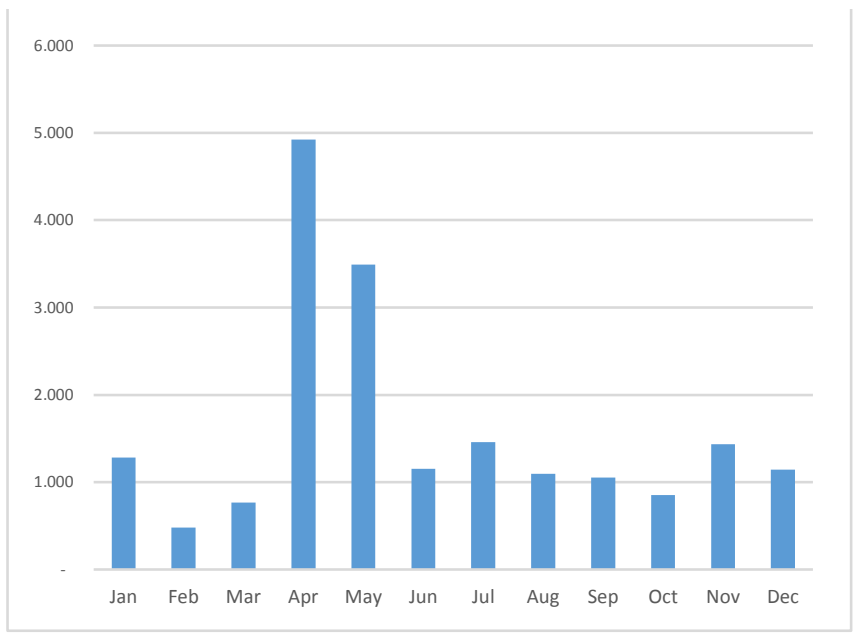

Fig.6 Average poultry litter production

\section{System design \& analysis}

In this on-grid hybrid energy generation system of PV and Biomass, the three main components will include the PV panels, Biomass generator and grid are used to calculate the feasibility of this on grid connected hybrid energy generation system, HOMER is used to compare the different combinations of configurations from these 3 main components to fulfill the requirements of demanded load and achieve the lowest NPV and COE for the proposed system to reduce the operational cost. So, it is used to reach this target the search space feature at HOMER in which it is provided HOMER with available sizes at the market for both biomass generator and PV plant in addition to the available capacity of energy exchange with national grid through the overhead transmission line to compare between different configuration to find the most optimum configuration and sizing that meets the load requirements. The modeling of those components at HOMER will be as follows.

\subsection{Photovoltaic panels}

In proposed study, HOMER has searched at several available solar modules of different capacities in blend with the generator of biomass through the search space option for the sizing of $\mathrm{PV}$ plant to meet the requirement of load during the daily profile of highest peak demanded load. It is used in this mode polycrystalline silicon Photovoltaic modules 's type with a MAX. rated power of $250 \mathrm{~W}$ [16], the nominal voltage of $31.02 \mathrm{~V}$, plus current of operation is around $8.06 \mathrm{~A}$. the initial cost of the photovoltaic arrays in Egypt is $2500 \$ / \mathrm{kW}$ [16] with expecting lifetime of 25 years. The full details of solar modules used for modeling and simulating are itemized in Table 4.
Table 4. Photovoltaic Panel parameters

\begin{tabular}{|c|c|c|c|}
\hline No. & Parameter & Unit & Value \\
\hline 1 & Capital cost & $\$ / \mathrm{kW}$ & 2500 \\
\hline 2 & Replacement cost & $\$ / \mathrm{kW}$ & 1500 \\
\hline 3 & O \& M cost & $\$ / \mathrm{kW}$ & 10 \\
\hline 4 & De-rating factor & $\%$ & 80 \\
\hline 5 & Lifetime & Years & 25 \\
\hline 6 & $\begin{array}{c}\text { Temperature } \\
\text { Coefficient }\end{array}$ & percent & -0.5 \\
\hline 7 & $\begin{array}{c}\text { Operating } \\
\text { Temperature }\end{array}$ & ${ }^{0} \mathrm{C}$ & 47 \\
\hline 8 & Efficiency & $\%$ & 13 \\
\hline
\end{tabular}

\subsection{Biomass generator}

To meet the $9660 \mathrm{kWh}$ daily electrical load of the existing farm, the biomass generator of different capacities was determined from the available capacities [17] of biomass generators from POWERMAX company to size this biomass generator which will be simulated with different configurations and available sizes and capacities of PV modules in addition to the available capacity of energy exchange with grid. It is used the Biomass generator to mitigate the effect of unavailability of solar energy at night on the stability of internal farm's grid as long as reduce the cost of operation in addition to mitigate the environmental effect of using poultry litter in its fundamental form as fertilizer as per the existing situation. One of the potentials also of using waste to energy technology to fulfill the demanded load requirement is the cost of fuel which will be considered zero consequently it will have a great impact on the total cost of operation of the Farm. According to [17], the energy generated from $1.0 \mathrm{~kW}$ biomass generator from poultry litter will cost $500 \$ /$ $\mathrm{kW}$, includes the cost of installations. Generator associated costs and other technical parameters used in simulation are listed in Table 5.

Table 5. Biomass generator parameter

\begin{tabular}{|c|c|c|c|}
\hline No. & Parameters & Units & Values \\
\hline 1 & Capital Cost & $\$ / \mathrm{kW}$ & 500 \\
\hline 2 & Replacement Cost & $\$ / \mathrm{kW}$ & 500 \\
\hline 3 & Lifetime & Hours & 15,000 \\
\hline 4 & Minimum Load \% & percent & 25 \\
\hline 5 & O \& M cost & \$/op.hr & 0.03 \\
\hline
\end{tabular}

\subsection{National electrical grid role}

In this project, the National electrical grid is used as a backup for hybrid system PV- Biomass. this is due to different reasons. The first one is a high rise in temperature at this location, which will negatively effect on lifetime of batteries, so it will be required to store them in a cooled location, that consequently will increase the cost, on the other hand, the availability of the grid extension to this location. The location of the 
farm is near to BAN BAN solar plant, so the National electrical grid is extended to the location of the farm. The second reason for using the grid as a backup for this project is a new law, No. 203 [18], that issued in 2014 in Egypt. The law encourages the private sector to sell and purchase electricity with National grid using the net-metering system through renewable energy generation units.

The net-metering system depends on the calculation of purchased and selling energy during the month. In case the sold energy increases the excess of the purchased energy, it will be added to the next month. By the end of the year, if the sold energy exceeds the purchased energy, the national electric company will purchase this excess of sold energy with the cost of producing energy in which the Egyptian ministry of electricity updates this cost each year.

This law maximizes the potential of using the National electrical grid as a backup for the farm during the lower energy production from the hybrid PVBiomass power plant as well as using as storage in case of excessing of energy production from PV plant during the daytime. It also enhanced the stability of the farm's grid.

In this model, the value of $0.07 \$ / \mathrm{kWh}$ for purchased energy from the grid and $0.05 \$ / \mathrm{kWh}$ for selling energy to the grid are entered at HOMER. On the other hand, it is entered in the model the cost of peak demand rate, which is $3.75 \$ / \mathrm{kW} /$ month. All the previous rates it is gotten from the ministry of electricity website [18] for 2019. It is assumed $1 \$=16$ Egyptian pounds.

\subsection{Analysis}

National renewable energy laboratory (NREL) designed HOMER software to deliver the designers of system with techno-economic feasibility report of the project. The primary objective of the HOMER is to reduce the net present cost (NPC) as well as the cost of operation for the best various configuration of energy generation system depends on the different inputs. the annual discount rate of $8 \%$ [18] Will be considered during 25 years of lifetime of the project for the economic analysis. after the economic analysis, the HOMER software simulated the lowest COE and NPC configuration according to the load needs at the farm Capability of poultry litters production and the available of solar radiations, which diverse to evaluate the chosen configuration costs of operation throughout the diverse loads thru the time of day, month, and year.

\section{Results}

At this proposal, a hybrid energy generation of $\mathrm{PV} /$ Biomass grid-connected system designed to meet the requirements of the poultry farm to use it in electrical uses inside the farm. Using HOMER software simulated the system to enhance the selected configurations of energy generation system matching to the profile of load, as well as the attained results are presented in the following.

\subsection{Optimization}

HOMER optimizes the sizing of proposed configuration of grid connected biomass and photovoltaic energy generation system by searching in available capacity of biomass generator and photovoltaic modules in market which had inserted in software before to find the best suitable size and economic to meet the requirement of the load at poultry farm. In this model, the search space feature is used instead of the HOMER optimizer. The search space is essential to identify degradation or growth in terms of a percent each year. It is abled also to submit a year-byyear series of multipliers to meet a forecast that is not purely a percentage per year.

The multiyear module combines several features to HOMER's results. It is examined each year of the project life in the simulation results. The multiyear module also adds the multiyear plot, which allows us to plot any result quantity over the life of the project.

In search space for the capacity range of $\mathrm{PV}$, it was in range of $200 \mathrm{~kW}$ to $1800 \mathrm{~kW}$, for biomass generator, the generator was different from 400 to $2000 \mathrm{~kW}$, in HOMER, it used the search space feature to choose the suitable capacity of each component of configuration to fulfill the demand requirements. It was found that the most optimal configuration of the proposed configuration at this study will consist of the diverse renewable components including $500 \mathrm{kWp}$ of photovoltaic modules \& $400 \mathrm{~kW}$ biomass generator ensued. Those capacities were considered as the best techno-economic configuration simulated, as displayed in Fig. 7. HOMER sorted these optimized results. It is sorted on the base of COE, NPC, and investment of the initial capital. HOMER simulated different configurations for same components of system which had same the ability to meet the same energy demand using different sizing of components.

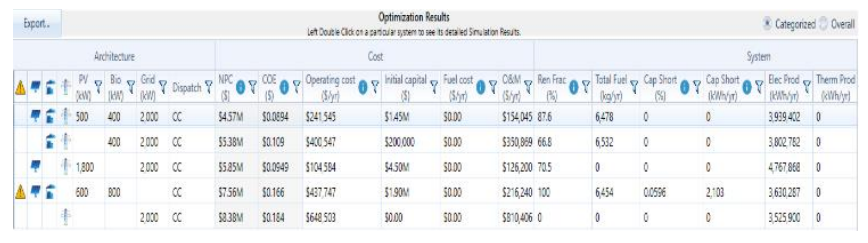

Fig.7 Optimization results

\subsection{Production summary}

In Table 6, it is compared electrical production in $\mathrm{kWh}$ per year at the 1st year and 25th year of the project for the components of winning configuration. It is reviewed the first and 25th-year data of the project because most of the changes happened at 1 st year of the project. It 
remains almost constant until the project ended, which will appear later. It is clear from Table 6 that the percent of participating in energy production of PV plant remains almost constant during the lifetime of the project while the participation percent of biomass generator increases significantly and decreasing purchased energy from the grid during lifetime of the project to be only $10.6 \%$ of total energy consumed. This is due to $\mathrm{COE}$ of grid at the beginning of the project is better than $\mathrm{COE}$ from biomass while this $\mathrm{COE}$ of grid is starting to increase by $8 \%$ annually and $\mathrm{COE}$ of biomass is still constant which will become feasible to depend more on Biomass energy than to depend on grid and purchase only the amount of energy that Biomass generator and solar energy cannot generate it. It appears clearly this purchased amount from the grid is used to keep the stability of grid at the farm level due to penetration of renewable energy. COE of solar energy is kept constant during the lifetime of the project which is less than grid and biomass so the total production of Solar energy is used either on the load level or the excess is sold to grid to reuse it again during night with biomass generator.

Table 6. Production Summary of winning architecture

\begin{tabular}{|l|l|l|l|l|}
\hline $\begin{array}{c}\text { Compon } \\
\text { ent }\end{array}$ & $\begin{array}{c}\text { Total } \\
\text { energy } \\
\text { at } \mathbf{1}^{\text {st }} \\
\text { year }\end{array}$ & $\begin{array}{c}\text { Energy } \\
\text { percent } \\
\text { at } \mathbf{1}^{\text {st }} \\
\text { year }\end{array}$ & $\begin{array}{c}\text { Total } \\
\text { energy } \\
\text { in 25 } \\
\text { year }\end{array}$ & $\begin{array}{c}\text { Energy } \\
\text { Percent } \\
\text { at 25 } \\
\text { year }\end{array}$ \\
\hline PV plant & $\begin{array}{l}933,68 \\
7\end{array}$ & 25.2 & 933,687 & 23.9 \\
\hline $\begin{array}{l}\text { Biomass } \\
\text { Generato } \\
\text { r }\end{array}$ & $\begin{array}{l}1,575, \\
200\end{array}$ & 42.8 & $\begin{array}{l}2,555,0 \\
00\end{array}$ & 65.4 \\
\hline $\begin{array}{l}\text { Grid } \\
\text { Purchase } \\
\text { s }\end{array}$ & $\begin{array}{l}1,164, \\
733\end{array}$ & 31.7 & 415,092 & 10.6 \\
\hline Total & $\begin{array}{l}3,677, \\
527\end{array}$ & 100 & $3,903,7$ & 100 \\
\hline
\end{tabular}

\subsection{Monthly Electric Production}

It is used to compare the electrical production per component in Fig. 8 and Fig. 9 of the winning generation system at 1 st year and the 25th year to illustrate the contribution of each Component in the generation during the project lifetime. It is clear that the generation from biomass increases during the project lifetime. The electric energy purchased from the grid will decrease during the project, which one of the main goals of the project to decrease dependence on the grid and uses it as a backup for the hybrid system. PV energy generation will almost keep constant during the project. The contribution of biomass energy increases because of a gradual increase in the cost of energy purchased from the grid beside the cost stability of the production of biomass energy as the cost of fuel is zero.

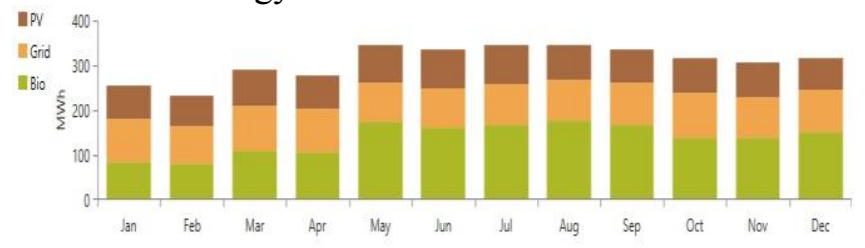

Fig.8 Monthly electric productions at 1st year

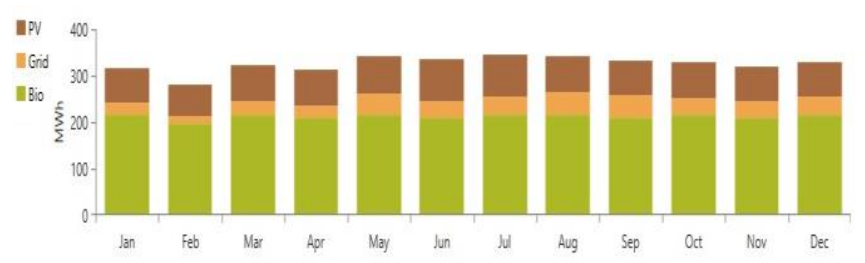

Fig.9 Monthly electric productions at 25th year

\subsection{Biomass generator}

In Fig. 10, the electrical energy production of the biomass generator will increase during the first year of the project then continue steadily until the end of the project.

In Fig. 11, the mean output of biomass generator will decrease during the first nine years of the project then remain constant but at the same time, the number of operating hours of biomass generator as to keep the energy production remain constant which means at the beginning of the project, the biomass generator will cover part of the load. It is due to the cost of Energy (COE) of biomass energy, which keeps constant versus $\mathrm{COE}$ of the grid.

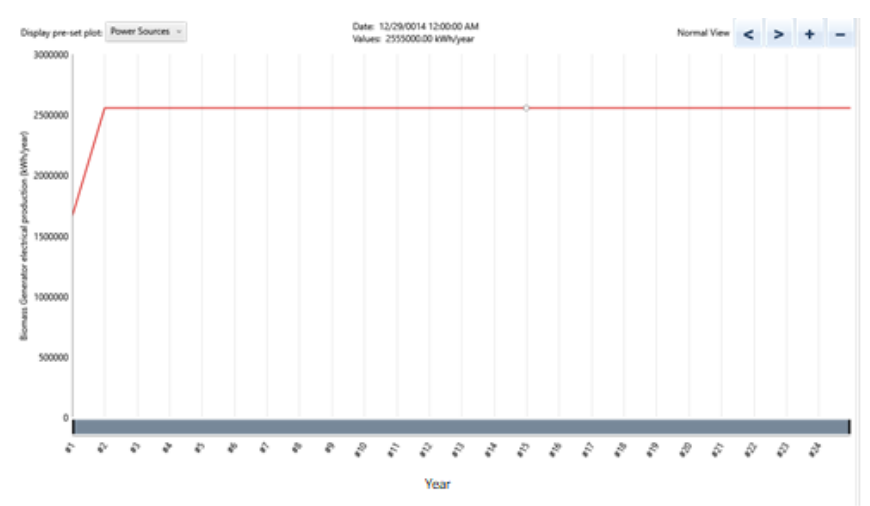

Fig.10 Electrical production of biomass generator 


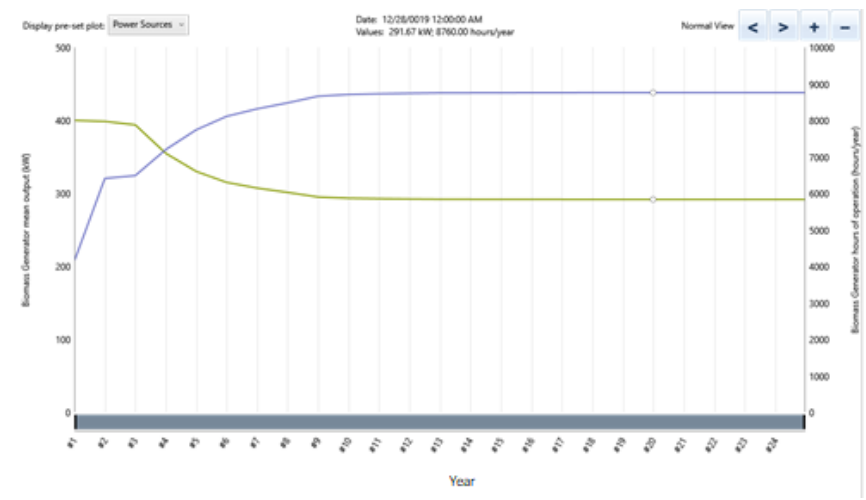

Fig.11 the mean output of biomass generator $(\mathrm{kW})$ and operating hours

\subsubsection{Fuel Consumption}

In Fig. 12, the consumption of fuel will increase during the first year of the project then remain constant until the end of the project, which means that the biomass generator will be used at peak hours during first year of project lifetime On the other hand, starting from 2nd year of the project till the end, the consumption of fuel will be the same, which means the total energy demand from the biomass generator will also be constant. As $\mathrm{COE}$ of grid is increasing by $8 \%$ after first year of the project and COE of biomass is still constant.

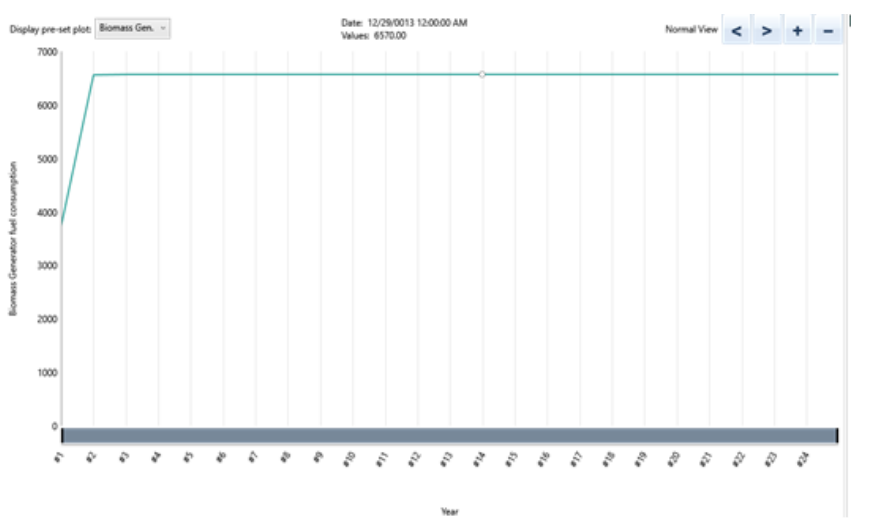

Fig.12 Liter consumption of Biomass generator

\subsubsection{Biomass Generator Multiyear Trends (Percent of First-Year Value)}

In Fig. 13, it illustrates the multiyear trends of Biomass generator's operation characteristics during the project. Gradually the number of working hours of biomass generator increases till it reaches more than $200 \%$ of the number of operating hours that generator used at the beginning of the project .it will remain constant starting from the $10^{\text {th }}$ year. In the same vein as the number of starts of biomass generator increases in the first three years of the project, then start to decrease until it vanishes in the $10^{\text {th }}$ year of the project. These changes mean that biomass power generation will substitute depending on energy from the grid, and this dependence will increase gradually through the life of the project and decrease depending on the grid.

The mean output of biomass will decrease in the first seven years of the project. The minimum output power will start to decrease starting from the 1st year of the project and remains constant starting from the 4th year of the project. The maximum output power will remain constant until the $18^{\text {th }}$ year of the project, then reduce and will remain constant until the end of the project.

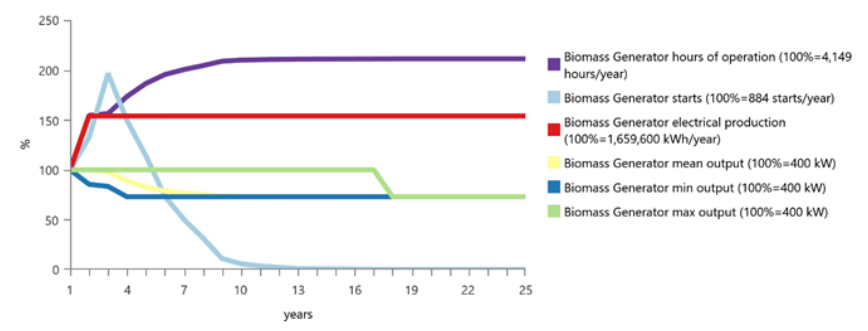

Fig.13 Biomass generator Multiyear trends

\subsection{PV plant}

The output power and energy produced from the PV plant remain almost constant during the project lifetime, as illustrated in Fig. 14, and Fig. 15.

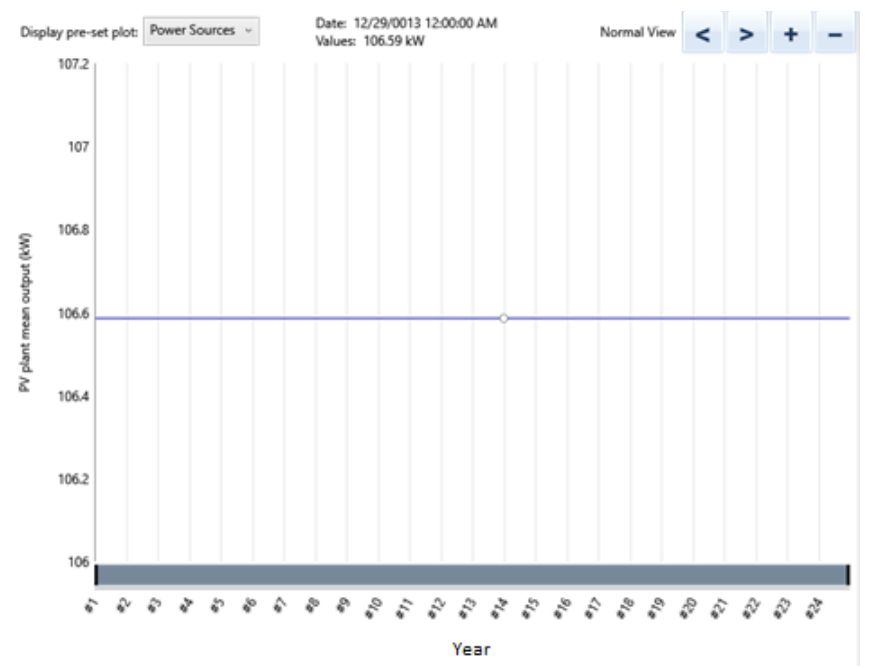

Fig.14 PV plant mean output power 


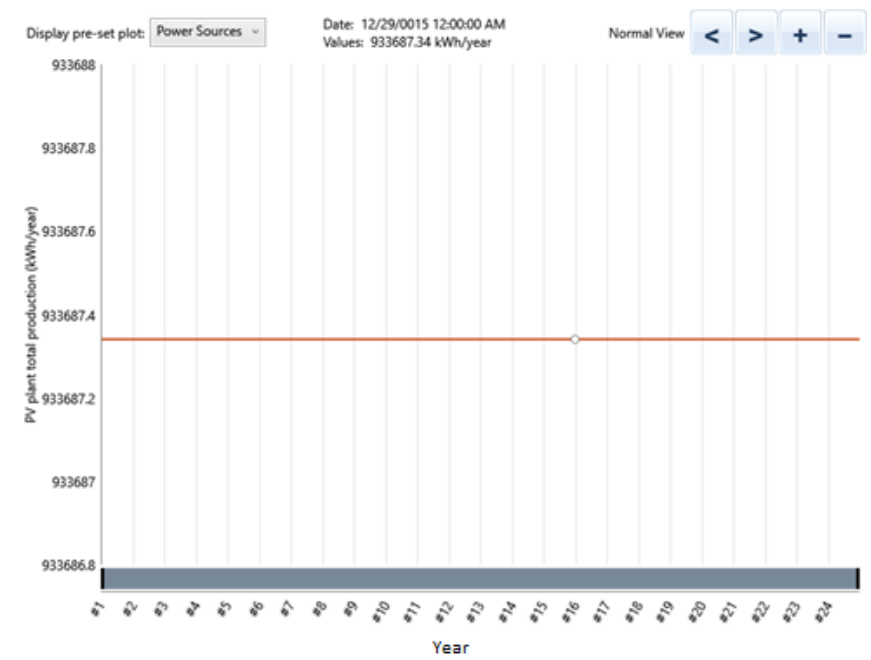

Fig.15 PV plant energy production (kWh.)

\subsection{Electrical grid simulation results}

\subsubsection{Energy purchased and energy sold}

In Fig. 16, It appears the total energy purchased per year from the grid, total energy sold per year to the grid, and the net of energy purchased from the grid. The net of energy purchased decreases lower than $700 \mathrm{MWh}$ at 2nd year of the project until the end of the project. The decreased at depending on using the grid and increased using the power generated by Biomass generator and $\mathrm{PV}$. as the price of purchased energy increases by $8 \%$ each year.

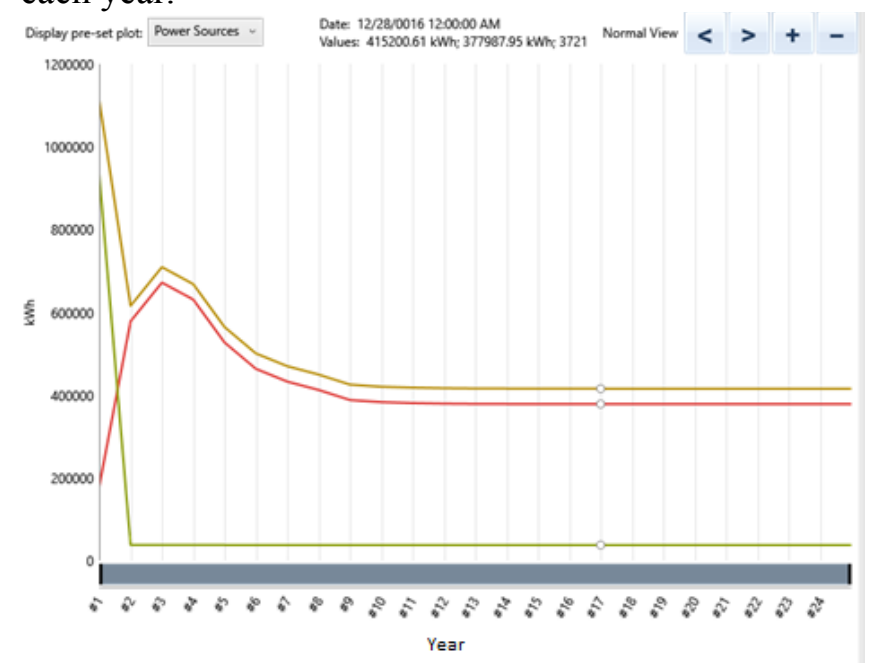

Fig.16 Energy purchased and Sold

\subsubsection{Energy charge Multiyear trends (Percent of First-Year Value)}

Fig. 17 shows the total energy charge during the lifetime of the project. The charge of energy decreases rapidly during the first year of the project it will slightly increase during the project until it reaches $20 \%$ of the charge in the first year of the project. This increase is due to that part of energy power. The farm consists of Energy from grid, where its price increases gradually.

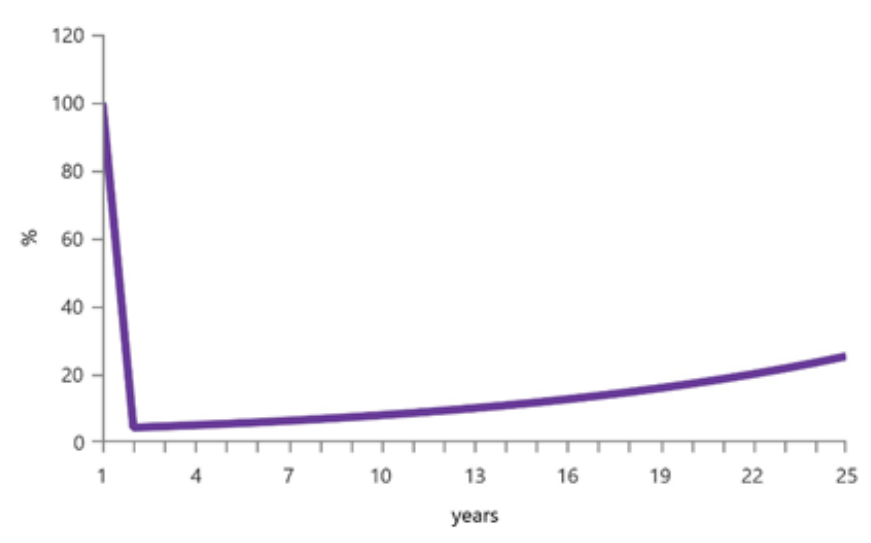

Fig.17 Energy charge Multiyear Trends

\subsection{Economics}

\subsubsection{Cost Summary}

According to Fig. 18 and Table 7, it shows that the highest capital cost is the PV plant, while the highest operating cost and replacement is due to the biomass generator.

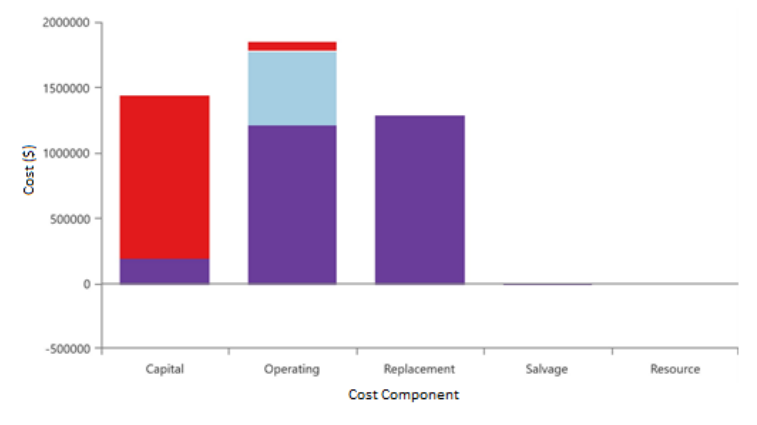

Fig. 18 Cost Summary

Table 1 Net Present Costs (\$)

\begin{tabular}{|c|c|c|c|c|c|}
\hline Name & $\begin{array}{c}\text { Capi } \\
\text { tal }\end{array}$ & $\begin{array}{c}\text { Opera } \\
\text { ting }\end{array}$ & $\begin{array}{c}\text { Replace } \\
\text { ment }\end{array}$ & $\begin{array}{c}\text { Salv } \\
\text { age }\end{array}$ & Total \\
\hline $\begin{array}{c}\text { Bioma } \\
\text { ss } \\
\begin{array}{c}\text { Gener } \\
\text { ator }\end{array}\end{array}$ & $200 \mathrm{~K}$ & $1.22 \mathrm{M}$ & $1.29 \mathrm{M}$ & $\begin{array}{c}- \\
14,0 \\
80\end{array}$ & $\begin{array}{c}2.70 \\
\mathrm{M}\end{array}$ \\
\hline Grid & 0.00 & $\begin{array}{c}559,34 \\
6\end{array}$ & 0.00 & 0.00 & $\begin{array}{c}559,3 \\
46\end{array}$ \\
\hline $\begin{array}{c}\text { PV } \\
\text { plant }\end{array}$ & $\begin{array}{c}1.25 \\
\mathrm{M}\end{array}$ & 64,638 & 0.00 & $\begin{array}{c}\$ 0.0 \\
0\end{array}$ & $\begin{array}{c}1.31 \\
\mathrm{M}\end{array}$ \\
\hline $\begin{array}{c}\text { Syste } \\
\mathrm{m}\end{array}$ & $\begin{array}{c}1.45 \\
\mathrm{M}\end{array}$ & $1.85 \mathrm{M}$ & $1.29 \mathrm{M}$ & $\begin{array}{c}14,0 \\
80\end{array}$ & $\begin{array}{c}4.57 \\
\mathrm{M}\end{array}$ \\
\hline
\end{tabular}

\subsubsection{Cash flow}

As per Fig. 19, the highest cost in the first year of the project is the initial cost of the system, especially the PV plant, while during the lifetime of the project, the 
highest cost will be the operating cost of biomass generator.

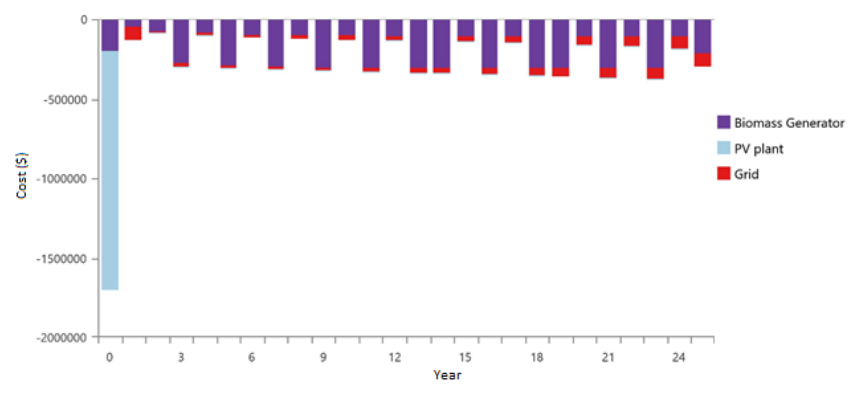

Fig.19 Cash Flow of the project by Component

\subsubsection{Economics Comparison}

In Table 8, the base case is the present case in which the grid powered the farm while the current system is the winner configuration of biomass generator, PV plant, and grid. It is clear from Table 8 the Net present cost (NPC) of the current system is lower than the base case, which significantly effects on Levelized cost of Energy (LCOE). The LCOE of the current system is around $48 \%$ of the LCOE of the base case. It appears clearly in OPEX in which the OPEX of the current system is around $35 \%$ of OPEX of the base case.

Table 2 Economics Comparison

\begin{tabular}{|c|c|c|}
\hline Item & Base Case & $\begin{array}{c}\text { Current } \\
\text { System }\end{array}$ \\
\hline Net Present Cost & $\$ 8.38 \mathrm{M}$ & $\$ 4.67 \mathrm{M}$ \\
\hline CAPEX & $\$ 0.00$ & $\$ 1.70 \mathrm{M}$ \\
\hline OPEX & $\$ 648,503$ & $\$ 230,052$ \\
\hline LCOE (per kWh) & $\$ 0.184$ & $\$ 0.0896$ \\
\hline $\begin{array}{c}\mathrm{CO}_{2} \text { Emitted } \\
(\mathrm{kg} / \mathrm{yr})\end{array}$ & $2,228,369$ & 292,780 \\
\hline $\begin{array}{c}\text { Fuel Consumption } \\
(\mathrm{L} / \mathrm{yr})\end{array}$ & 0 & 6,456 \\
\hline
\end{tabular}

\section{Conclusion}

With the rapid development of the economy, sustainable development and energy security are becoming significantly prominent. Gradually, renewable energy gains more attention and shows an essential role in current and future development. Renewable energy will gradually replace fossil fuels [19-20], but in a long-time period. Solar and Biomass Energy are newly developed sustainable resources with much scope for development in Egypt.

The mentioned Farm has a great potential of implementing and merging renewable energy using the grid to reduce the operational cost and add some resilience dimensions to the existing situation of farm. The annual average solar insulation at the location at this proposed farm in Egypt is $6.24 \mathrm{kWh} / \mathrm{m}^{2} /$ day and the annual average poultry litter production of the farm is approximately 18 tones daily.
The current work has 3 purpose dimensions the first dimension is to study the economic feasibility impact of using the hybrid PV - biomass grid-connected power system to power existing poultry farm in Egypt from an economic perspective to decrease the cost of operation. The second dimension is mitigating the environmental impact of poultry litter generated from this farm on surrounding community and using it as benefit instead of considering it as problem through using waste to energy technology. The third dimension is to decrease depending on the fossil fuel to generate electricity and using the renewable energy to enhance the resilience and redundancy of power generation to this farm using existing renewable energy at this location.

The hybrid PV-wind-biomass power system was modeled and analyzed by HOMER simulation software. The best suitable design with high economic value includes $500 \mathrm{~kW}$ PV panels, $400 \mathrm{~kW}$ biomass generators. It can potentially produce enough electricity to meet the load demand of the farm. The initial cost for this system is about 1.45 million US dollars, which is quite high if it compared with the case of using electrical grid which is the exist situation. However, if it is considered the increase in the cost of kilowatt-hours of electricity of grid at each year by $8 \%$ the benefits will be significantly enhanced, and the cost of energy would drop to $0.0894 \$$ versus if it was continued using the grid which will be $0.184 \$$ in case of using the grid in coming years without shifting to use the existing renewable energy resources available at the farm. Furthermore, replacing fossil fuels with renewable energies in the electrification sector can also contribute positively to reducing $\mathrm{CO}_{2}$ emission. reducing depending on the grid as main source of energy which was at first of year of the project was $30 \%$ and then reduced again to be $10 \%$ during the lifetime of the project will add resilience and redundant dimensions of using renewable energy to the project.

\section{Recommendations and future work}

For future work, Egypt had a high potential of using solar Energy with Biomass in the generation of electricity so it should be based on:

1. Continued study on the subject and improved the hybrid system to a grid-connected system.

2. Study the feasibility of using biomass resources found in Egypt in conversation to electrical energy.

3. Do tests and analyses to find if biomass prices have an impact on the feasibility of the system.

4. Do more economic analysis to propose a suitable and realistic electricity price in case of using large scale poultry litter in electrical generation plants.

5. Do more studies on improving the efficiencies of poultry biomass generators. 


\section{References}

[1] Singh, Kanwardeep, Gagandeep Guide Kaur, and Souvik Guide Ganguli. Study of solar/biogas hybrid power generation. Diss. 2010.

[2] Sen, Rohit, and Subhes C. Bhattacharyya. "Offgrid electricity generation with renewable energy technologies in India: An application of HOMER." Renewable Energy 62 (2014): 388398.

[3] Balachander Kalappan, Dr, and Vijayakumar Ponnudsamy. "Modeling, Simulation and Optimization of Hybrid Renewable Power System for Daily Load demand of Metropolitan Cities in India." Computer 1: 150.

[4] Lynch, Deirdre, et al. "Utilisation of poultry litter as an energy feedstock." Biomass and bioenergy 49 (2013): 197-204.

[5] Balamurugan, P., S. Kumaravel, and S. Ashok. "Optimal operation of biomass gasifier based hybrid energy system." ISRN Renewable Energy 2011 (2011).

[6] S.G. Wiedemann, Energy recovery from litter: a guide for users, RIRDC Publication No. 14/096, july 2015.

[7] Ghasemi, Abolfazl, et al. "Techno-economic analysis of stand-alone hybrid photovoltaicdiesel-battery systems for rural electrification in eastern part of Iran-A step toward sustainable rural development." Renewable and Sustainable Energy Reviews 28 (2013): 456-462.

[8] Harish Kumar Jeswani, Andrew Whiting, Alastair Martin, Adisa Azapagic, "Environmental and economic sustainability of poultry litter gasification for electricity and heat generation", waste management 95 (2019) : 182-191.

[9] Shahzad, M. Kashif, et al. "Techno-economic feasibility analysis of a solar-biomass off grid system for the electrification of remote rural areas in Pakistan using HOMER software." Renewable energy 106 (2017): 264-273.

[10] Abdelbadea, M., T. A. Boghdady, and D. Khalil Ibrahim. "Enhancing active radial distribution networks by optimal sizing and placement of DGs using modified crow search algorithm." Indonesian Journal of Electrical Engineering and Computer Science 16.3 (2019): 1179-1188.

[11] Boghdady, T. A., M. M. Sayed, and Howaida M. Ragab. "Wind Energy Conversion System Oscillations Damping Using a Proposed Mutation Operator for LBBO-DE Algorithm." 2019 21st International Middle East Power Systems Conference (MEPCON). IEEE, 2019.

[12] Boghdady, T. A., and M. M. Sayed. "Improving the performance of HVDC system using Fuzzy PI controller tuned by Linearized BiogeographyBased Optimization Algorithm." (2018): 12-5.

[13] S. Bajaj, K. S. Sandhu, Effect of Site and Size of Wind Turbine on its Economic Operation, International Journal of Circuits, Systems and Signal Processing, Volume 13, 2019, pp. 237-242.

[14] Ayman M. Mansour, Jalal Abdallah, Mohammad A. Obeidat, An Efficient Intelligent Power Detection Method for Photovoltaic System, International Journal of Circuits, Systems and Signal Processing, Volume 14, 2020, pp. 686-699.

[15] Dalólio, Felipe Santos, et al. "Poultry litter as biomass energy: A review and future perspectives." Renewable and Sustainable Energy Reviews 76 (2017): 941-949.

[16] S. Derek Mitchell, Hyundai HiS-M250RG (250W) Solar Panel [online], 2016.Available at: Solardesigntool.com

http://www.solardesigntool.com/components/mod ule-panel-solar/Hyundai/2584/HiS-

M250RG/specificationdata-sheet.html (Accessed 29 December 2016).

[17] PowerMax gaisifer, Chicken Manure Gasification Power Plant, 2020[online]Available at:http://www.powermaxgasifiers.com/index.php? ac $=$ article \&at $=$ read $\&$ did $=257$

[18] Law Number 203 issues 2014, Minister of electricity and renewable resources available at http://www.nrea.gov.eg/Investors/Legi.

[19] Miles, Dana M., et al. "On-farm resources and renewable energy in broiler chicken production: brinson farms case study." International Journal of Poultry Science 15.2 (2016): 41-47.

[20] Bob Boundy, Susan W. Diegel, Lynn Wright, Stacy C. Davis, Biomass Energy Data Book: Edition 3, 2011.

\section{Creative Commons Attribution License 4.0 (Attribution 4.0 International, CC BY 4.0)}

This article is published under the terms of the Creative Commons Attribution License 4.0

https://creativecommons.org/licenses/by/4.0/deed.en US 